\title{
Knowing Your Place: Self-Perceptions of Status in Face-to-Face Groups
}

\author{
Cameron Anderson \\ University of California, Berkeley
}

Jennifer S. Beer

University of California, Davis

\author{
Sanjay Srivastava \\ University of Oregon
}

Sandra E. Spataro
Cornell University

Jennifer A. Chatman

University of California, Berkeley

\begin{abstract}
Status is the prominence, respect, and influence individuals enjoy in the eyes of others. Theories of positive illusions suggest that individuals form overly positive perceptions of their status in face-to-face groups. In contrast, the authors argue that individuals' perceptions of their status are highly accuratethat is, they closely match the group's perception of their status- because forming overly positive status self-perceptions can damage individuals' acceptance in a group. Therefore, the authors further argue that individuals are likely to refrain from status self-enhancement to maintain their belongingness in a group. Support for their hypotheses was found in 2 studies of status in face-to-face groups, using a social relations model approach (D. A. Kenny \& L. La Voie, 1984). Individuals showed high accuracy in perceiving their status and even erred on the side of being overly humble. Moreover, enhancement in status self-perceptions was associated with lower levels of social acceptance.
\end{abstract}

Keywords: status, self-perception, self-enhancement, positive illusions, social relations model

"I'm in control here." Alexander M. Haig uttered these infamous words at a press conference after the shooting of President Ronald Reagan on March 30, 1981. As secretary of state, Haig was actually fourth in the line of succession and did not have executive authority. According to many reports, Haig's claim was emblematic of his general attitude while U.S. secretary of state. Haig apparently had an overinflated view of his status in the Reagan White House- he felt entitled to more authority than the president over foreign policy issues, treated highly ranked colleagues with little respect, and demanded many high-status privileges, such as a better seat on the president's airplane, Air Force One (Weisman, 1982).

In turn, fellow cabinet members reportedly bristled at Haig's inflated self-perception. They fought with him repeatedly on policy issues, generally excluded him from daily interactions, and ridiculed him so extensively in the press that one political observer remarked, "The public beating Mr. Haig received at the hands of the White House was virtually unprecedented" (Gelb, 1981, p. 23). Under these circumstances, it is not surprising that Haig resigned after only a year and a half.

Cameron Anderson and Jennifer A. Chatman, Walter A. Haas School of Business, University of California, Berkeley; Sanjay Srivastava, Department of Psychology, University of Oregon; Jennifer S. Beer, Department of Psychology, University of California, Davis; Sandra E. Spataro, Johnson Graduate School of Management, Cornell University.

Correspondence concerning this article should be addressed to Cameron Anderson, University of California, Walter A. Haas School of Business, 545 Student Services Bldg \#1900, Berkeley, CA 94720-1900. E-mail: anderson@haas.berkeley.edu
Haig's volatile tenure as secretary of state and the termination of his political career illustrate the primary arguments we put forth in this article about the consequences of overestimating one's status in face-to-face groups. Status in face-to-face groups is the prominence, respect, and influence individuals enjoy in the eyes of other group members (Anderson, John, Keltner, \& Kring, 2001; Berger, Cohen, \& Zelditch, 1972; Goldhamer \& Shils, 1939). We argue that status self-enhancers-individuals who believe they possess higher status in a group than is actually accorded to them by the group - are disliked and rejected by other group members because they are seen as illegitimately demanding social privileges and trying to usurp control from others. We further argue that to prevent social rejection, individuals tend to avoid engaging in status self-enhancement, instead perceiving their status relatively accurately; in other words, individuals try to avoid Alexander Haig's mistake of overestimating their own status. Our view contrasts with those offered by the positive illusions perspective, which suggests that individuals tend to form unrealistic, overly positive perceptions of themselves in a wide variety of domains to maintain their self-esteem (Barkow, 1975; Pfeffer \& Cialdini, 1998; Taylor \& Brown, 1988). We argue, instead, that status considerations offer an important exception to predictions made by the theory of positive illusions.

To evaluate these hypotheses, we conducted two laboratory studies of status in naturally interacting face-to-face groups, using a social relations model design (Kenny \& La Voie, 1984). In Study 1 , we examined the social consequences of status selfenhancement and the accuracy of self-perceptions of status using a longitudinal design. In Study 2, we again examined social consequences and accuracy. In addition, however, we tested whether 
individuals' concern for social acceptance kept them from engaging in status self-enhancement and whether status selfenhancement damaged groups' overall functioning.

\section{The Case for Self-Enhancement in Status Perceptions}

According to the prominent positive illusions perspective, people have a strong desire to view themselves positively, which can lead them to construct distorted, unrealistically positive selfperceptions (e.g., Greenwald, 1980; Taylor \& Brown, 1988). Researchers have found that people form overly positive selfperceptions on a variety of dimensions, including their intelligence (Kruger \& Dunning, 1999), physical abilities (Dunning, Meyerowitz, \& Holzberg, 1989), personality traits (Messick, Bloom, Boldizar, \& Samuelson, 1985), and physical attractiveness (Heine \& Lehman, 1997). This tendency to self-enhance is thought to stem from the broader motivation to maintain self-esteem (e.g., Baumeister, 1998; Dunning, Leuenberger, \& Sherman, 1995), and positive illusions are thought to have a number of personal and interpersonal benefits (Taylor \& Brown, 1988; Taylor, Lerner, Sherman, Sage, \& McDowell, 2003).

An individual's status in a face-to-face group has a strong impact on his or her self-esteem; that is, the level of respect and admiration individuals achieve in a group strongly shapes how they feel about themselves (Barkow, 1975; Frank, 1985; Heaven, 1986; Leary, Cottrell, \& Phillips, 2001; Raskin, Novacek, \& Hogan, 1991). Given the importance of status to bolstering selfesteem (Barkow, 1975), one might expect people to be especially likely to form distorted, overly positive perceptions of their status in face-to-face groups.

Indeed, a number of theorists have suggested that status selfenhancement is pervasive (Barkow, 1975; Krebs \& Denton, 1997; Pfeffer \& Cialdini, 1998). For example, Barkow (1975) argued that individuals typically distort status-relevant information to satisfy the imperative for self-esteem. They do so by ignoring some relevant information and emphasizing other information, which allows them to believe they possess higher status than they actually do. Pfeffer and Cialdini (1998) also argued that the drive for a positive self-concept leads individuals to form unrealistically positive perceptions of their influence over others' behavior. However, empirical studies of accuracy in self-perceptions have generally focused on constructs other than status, such as skills, abilities, or personality traits, leaving unanswered the question of whether self-enhancement biases shape perceptions of status in face-to-face group settings.

\section{The Case for Accuracy in Status Perceptions}

In contrast to arguments drawn from the positive illusions perspective, we propose that individuals avoid status selfenhancement because of the severe social costs a person might bear by inflating his or her status. On the basis of functionalist accounts of status (e.g., Thibaut \& Kelley, 1959), we propose that when members of face-to-face groups overestimate their status in the group, their behavior provokes conflict and disorganization, which in turn leads the group to dislike and reject that member. Therefore, individuals tend to refrain from engaging in status self-enhancement so that they can maintain their belongingness in groups (Baumeister \& Leary, 1995). Our perspective thus concurs with other researchers who have argued that self-enhancement in general has a number of deleterious effects (e.g., John \& Robins, 1994; Paulhus, 1998; Robins \& Beer, 2001).

\section{The Functions of Status Hierarchies in Face-to-Face Groups}

Status hierarchies serve a number of important functions for face-to-face groups. One of the primary challenges groups face is the division of influence among members. Groups often experience process inefficiencies because too many group members want to make decisions for the group, give out commands to others, and dominate group discussions, which can create chaos and conflict. Status hierarchies are a primary way groups solve this problem by facilitating an orderly division of influence among group members, using such means as allowing or denying different individuals the rights to perform certain behaviors (Bales, 1950; Berger, Rosenholtz, \& Zelditch, 1980). For example, high-status individuals are allowed to control group interactions, make decisions for the group, and give verbal directives to others, whereas low-status individuals are expected to defer to others, speak less in social interactions, and keep their opinions more to themselves (Bales, 1950; Berger et al., 1980; Goffman, 1967; Keltner, Gruenfeld, \& Anderson, 2003).

Groups also face the problem of self-interest. To succeed as a collective, groups must motivate members to act selflessly or to behave in ways that benefit the group, even when such behavior requires personal investment and sacrifice. Status hierarchies can help groups achieve this by rewarding individuals who contribute to the group's success (Berger et al., 1972; Blau, 1964; Frank, 1985; Homans, 1951; Thibaut \& Kelley, 1959). Face-to-face groups allocate status to group members who are believed to contribute to the group's goals; individuals believed to make important contributions to the group are typically granted high status, whereas individuals believed to make fewer contributions or even to undermine a group's success are assigned low status. Valued contributions can take several forms, such as expending effort for the group or providing needed expertise. By rewarding group-oriented behavior, status hierarchies compel individual members to work toward the group's goals, which facilitates collective success. ${ }^{1}$

\section{Hypothesis 1: Group Members Who Engage in Status Self-Enhancement Will Be Less Accepted by Other Members Than Those Who Perceive Their Status Accurately}

On the basis of this functional account of status hierarchies, we hypothesized that status self-enhancers would be less accepted by fellow group members than those who perceived their status accurately. Social acceptance is the degree to which individuals are liked by others and included in the group (Baumeister \& Leary,

\footnotetext{
${ }^{1}$ This functional perspective of status hierarchies contrasts with the view that status is allocated through dominance contests (e.g., Lee \& Ofshe, 1981; Mazur, 1973). Although the debate between these two perspectives has not been resolved, Ridgeway and colleagues have provided ample evidence that functional considerations play a major role in the statusorganizing processes of task groups (Ridgeway, 1987; Ridgeway \& Berger, 1986; Ridgeway \& Diekema, 1989).
} 
1995; Hogan, 1983). It involves how well individuals get along with others and is conceptually distinct from social status, which involves how well individuals get ahead (Hogan, 1983; Homans, 1951; Leary et al., 2001; Wiggins, 1979). We based our hypothesis on three converging lines of evidence.

First, because status hierarchies provide stability and order, face-to-face groups actively protect their status hierarchies by ostracizing and excluding individuals who challenge or subvert their hierarchy (e.g., Ridgeway, 1982; Ridgeway \& Berger, 1986). When individuals possess self-perceptions of status in a face-toface group that are higher than the status actually given to them by the group, they are likely to behave according to their own selfperceptions - by speaking frequently in group discussions, asserting their opinions forcefully, and making verbal commands and directives to others (Anderson \& Berdahl, 2002; Bugental \& Lewis, 1999; Galinsky, Gruenfeld, \& Magee, 2003). As a result of such behavior, status self-enhancers would instigate conflict and disorder in a group by refusing to defer to those who actually have higher status, attempting to take charge of the group, and working against those with higher status. They would be viewed by others as challenging and subverting the existing status order and undermining the stability of the group (Homans, 1951; Ridgeway \& Berger, 1986).

Second, status self-enhancers implicitly claim that they are making larger contributions to the group than others believe they are making. As mentioned above, status is a reward: It is a form of social currency that groups give to members who contribute to the group's success (Thibaut \& Kelley, 1959). When individuals engage in status self-enhancement in a face-to-face group, therefore, they are claiming more of this social payment than the group believes they are entitled to receive. Status self-enhancers would thus be less socially accepted because other group members would perceive them as claiming scarce social rewards that they did not deserve. ${ }^{2}$

Third, status self-enhancement may be threatening to fellow group members. Groups typically treat status as a zero-sum commodity, affording high status to a few individuals and giving lower status to others (Blau, 1964; Clark, 1990; Frank, 1985). When some individuals have high status, this necessitates that others have low status. Therefore, when individuals claim status for themselves, they take status away from others (Blau, 1964). For example, individuals who give unsolicited advice, interrupt others while speaking, or give verbal directives indicate that they perceive themselves to be superior to others (Clark, 1990). Status self-enhancers' expressed superiority, viewed as illegitimate by others, is likely to provoke harsh reactions from the group.

A few studies have provided suggestive evidence that selfenhanced perceptions of status can damage individuals' social acceptance. Early observational studies of peer groups found that when low-status group members tried to behave in high-status ways, such as by taking control of the group's activities, they were ridiculed and ostracized by other group members (Homans, 1951; Roethlisberger \& Dickson, 1938; Whyte, 1943). Studies of selfpresentational styles found that individuals who boasted were liked less than individuals with a more self-deprecating style (Jones \& Shrauger, 1970; Platt, 1977, cited in Powers \& Zuroff, 1986). Research on trait self-enhancement found that individuals who were generally high on self-enhancement were viewed by others as arrogant, hostile, cold, and defensive (Colvin, Block, \& Funder, 1995; Paulhus, 1998), suggesting they may have been less socially accepted. In the current studies, we extended these findings by directly testing the link between self-enhanced perceptions of status and social acceptance in groups.

\section{Social Costs for Status Self-Effacement?}

Our arguments and prior research suggest substantial costs associated with overestimating one's own status, but are there social costs associated with underestimation as well? That is, on a continuum from self-enhancement to accuracy to self-effacement, should one expect a linear relationship with social acceptance across the whole continuum or an inverted $U$-shaped curve, where self-effacers face social rejection just as self-enhancers do?

Strictly speaking, individuals who self-efface are violating a status hierarchy, and they might also be failing to perform leadership-related behaviors that the group is expecting them to perform. However, self-effacers are not claiming scarce social resources or threatening others' high status within the group; in fact, they are making more of both resources and social status available to others. Past research has suggested that status selfeffacers might be more socially accepted than accurate perceivers because they signal a particularly high degree of selflessness or an extreme willingness to put the group's interests above their own (Ridgeway, 1982). Given these various considerations, we found no strong basis to hypothesize a curvilinear relationship, though we considered it an important enough question to test in the data.

\section{Hypothesis 2: Face-to-Face Group Members Will Perceive Their Own Status Accurately}

If Hypothesis 1 is correct and status self-enhancement decreases social acceptance, people have an incentive to view their status accurately. We agree that people might desire to engage in status self-enhancement to maintain their self-esteem (e.g., Barkow, 1975; Pfeffer \& Cialdini, 1998). However, people also have a fundamental human need to belong and be included in social groups (Baumeister \& Leary, 1995; Maslow, 1968). According to Hypothesis 1, status self-enhancement would work against this second motive. Consistent with prior theorizing (e.g., Baumeister \& Leary, 1995), we believed that individuals' need to belong would outweigh their desire for higher self-esteem. Thus, our second hypothesis was that individuals' self-perceptions of status would be accurate. ${ }^{3}$

In considering accuracy, we adopted peer-rated status as the criterion against which self-perceptions would be compared. So-

\footnotetext{
2 This argument is not meant to imply that status-organizing processes are always fair. Groups allocate status to those they believe contribute to the group. Yet group perceptions can be misguided, as when individuals' status is based on demographic characteristics such as race or sex rather than on contributions to the group. That notwithstanding, once a status order is established, individuals who believe they possess more status than the group believes they possess will be less accepted.

${ }^{3}$ We hypothesized that individuals would accurately perceive their status, rather than underestimate it, because underestimating one's status would mean forgoing the social benefits that status affords, such as the ability to express one's opinions. Thus, although the need to belong would keep individuals from engaging in status self-enhancement, we believed the lure of reaping the benefits of status would keep individuals from being overly humble.
} 
cial perception researchers often face the dilemma that when an individual's self-perceptions diverge from peers' perceptions, it is unclear who has a stronger claim to truth (Robins \& John, 1997). However, status differs from other dimensions of social perception in an important way, in that status hierarchies are socially constructed: In a face-to-face group, the group members' perceptions are the very definition of status. Given this conceptualization of status, peer-rated status is an appropriate criterion for testing questions of accuracy.

Moreover, in social perception research, accuracy can mean many things both conceptually and operationally (Cronbach, 1955), and it is important to consider the definition of accuracy on which to focus. One definition provided by Cronbach (1955) is elevation accuracy, which is concerned with whether mean levels of self-perceptions are higher, lower, or about the same as others' perceptions. This is the sense of accuracy implied by the notion of self-enhancement versus self-effacement or of overestimating versus underestimating one's own status. If the average level of self-perceived status were higher than the average level of peerrated status, consistent with positive illusions predictions, we could conclude that the average individual self-enhances on status. In contrast, on the basis of our hypothesis that status selfenhancement has social costs, we expected that self-perceived status would be about equal to peer-rated status or perhaps even lower (if individuals were being overly modest in their status self-perceptions).

A second definition of accuracy is differential accuracy (Cronbach, 1955), which, in the present context, we defined as whether self-perceived status is positively correlated with peer-rated status. ${ }^{4}$ Whereas elevation accuracy is based on differences between mean levels of social perceptions, differential accuracy is concerned with the rank-order correspondence between selfperceptions and others' perceptions.

We expected to find evidence for both elevation accuracy and differential accuracy. However, elevation accuracy and differential accuracy are logically distinct, and it would not be necessary for them to give converging results. For example, it is possible that individuals might have little idea where they stand relative to others or within the status hierarchy of their group (poor differential accuracy), but when they estimate their own absolute status level, they might not be biased to be especially high or low (good elevation accuracy). Such a pattern in the data would still be somewhat consistent with Hypothesis 2 insofar as it would suggest that individuals were avoiding the pitfalls of overestimating their own status, but it would also suggest that individuals were not highly accurate in gauging their standing relative to others.

\section{Study 1}

For Study 1, we ran a longitudinal study of small groups. Groups of individuals began the study as relative strangers; they met and interacted once a week for 4 weeks. At the end of each meeting, participants rated status and social acceptance in a roundrobin design, wherein each participant in a group rated every other participant in that group and also provided self-ratings. Using Kenny and La Voie's (1984) social relations model, we were able to derive indices of the extent to which each individual was seen by other group members as having relatively high versus low status within the group and also whether each individual was relatively more versus less accepted in the group. The design also made it possible to derive indices of self-enhancement bias and to test questions about accuracy of self-perceptions using others' perceptions as the accuracy criterion.

\section{Main Hypotheses}

In Study 1, we examined two main hypotheses. First, we examined whether status self-enhancement led to lower levels of social acceptance (Hypothesis 1). The longitudinal design allowed us to test directionality by using lagged-effects analyses (Kenny \& Campbell, 1999; West, Biesanz, \& Pitts, 2000). If the analyses indicated that status self-enhancement at one point in time predicted social acceptance at a later point in time, this would support our hypothesis that groups are less accepting of individuals who engage in status self-enhancement. We also considered whether the lagged relationship from status self-enhancement to social acceptance was linear or curvilinear. That is, are individuals who self-efface (i.e., who underestimate their own status) met with more, less, or about the same amount of social acceptance as individuals who are fairly accurate or who self-enhance? To address this question, we also tested a cross-lagged model that included a quadratic effect of status self-enhancement on social acceptance.

Second, we tested whether self-perceptions of status were accurate (Hypothesis 2). We examined both elevation accuracy and differential accuracy (Cronbach, 1955). Elevation accuracy analyses are unlikely to show exactly zero differences between selfperceptions and peers' perceptions, and differential accuracy analyses are unlikely to show correlations of 1.0 between selfperceptions and peers' perceptions. Therefore, to provide a context for interpreting the analyses, we compared the elevation and differential accuracy of self-perceived status with the elevation and differential accuracy of self-perceived social acceptance.

Because of the special properties of status hierarchies, Hypothesis 1 applies specifically to status, not to self-enhancement on other social dimensions such as social acceptance. Unlike status, self-enhancement in domains such as social acceptance does not illegitimately claim scarce resources because social acceptance is not a scarce or zero-sum commodity (Blau, 1964). In fact, engaging in acceptance self-enhancement might only communicate an eagerness to be socially integrated and included. Previous research has shown that self-enhancement in many domains, including social acceptance, has either neutral (Srivastava \& Beer, 2005) or positive (Taylor et al., 2003) consequences for actual acceptance. Moreover, previous studies have consistently shown that, as predicted by the theory of positive illusions, individuals tend to overestimate themselves in most domains, including social acceptance (Kenny, 1994; Taylor \& Brown, 1988). Differential accuracy in many domains of self-perception, including social acceptance, can be substantial (Kenny, 1994); nevertheless, we expected differential accuracy to be even higher for status than for social acceptance.

\footnotetext{
${ }^{4}$ Our present treatment of differential accuracy is simplified somewhat from Cronbach's (1955) original decomposition, which operationalizes four components of accuracy in patterns of many trait ratings made at once (i.e., profiles) rather than ratings of a single characteristic at a time (in our case, status).
} 


\section{Additional Questions}

In addition to testing these main hypotheses, we also explored some additional issues relevant to our arguments. As part of the cross-lagged analysis, we were also able to conduct an independent test for effects in the reverse direction - to test whether being less accepted by others led to self-enhancement of status. It is possible, for example, that individuals who are less socially accepted might try to convince themselves that they have high status as a way to compensate for being disliked. This was posed as an additional exploratory question, not a rival to Hypothesis 1. In discussing cross-lagged models, Rogosa (1980) has written, "Measures of strength and duration of the reciprocal relationship and of the specific causal effects [italics added] are more informative than the determination of the causal winner" (p. 246). Consistent with this philosophy, we used the cross-lagged model to independently estimate the specific effects in each direction, and conceptually, we treated them as independent questions.

Another question concerned the possible effects of selfperceived status on one's actual status (i.e., status as attributed by peers). Although status self-enhancement might harm one's social acceptance, it is unknown whether it has consequences for actual status, and it is possible that positive beliefs about one's own status might act as a self-fulfilling prophecy (Jussim, 1991; Krebs \& Denton, 1997). For example, in one study, confederates who boasted about themselves were perceived as less likeable but also as more capable and less dependent on others (Gergen \& Wishnov, 1965), suggesting people might dislike self-enhancers but still concede high status to them. Because we assessed groups over time, we were able to test for a lagged effect of self-perceived status on actual status.

\section{Method}

\section{Participants}

Participants were undergraduate students attending a West Coast university who participated for course credit; the participants were 19 years old on average ( $S D=0.9$ years). The sample for the present study were restricted to those participants who came to all four sessions of the study and thus provided complete data $(N=152)$. The sample represented $72 \%$ of the total number of participants who attended the first week. Attrition analyses comparing complete-data participants with those who dropped out indicated no significant differences in status, social acceptance, or sex (all absolute $r \mathrm{~s}<.09$ ).

Participants were assigned to one of 28 groups that met once a week for 4 weeks; the great majority of participants were strangers (97\% of all possible pairings reported that they did not know one another at all, and fewer than $1 \%$ described their relationship as a preexisting friendship). The groups' size ranged from 4 to 8 , with a modal group size of 6 . The percentage of women in each group ranged from $25 \%$ to $80 \%$; the average percentage of women in each group was $50 \%$.

\section{Procedure}

Groups interacted for about 20 minutes the first week and for about 40 minutes all subsequent weeks. In Week 1 , we used a task that would allow group members to interact on a collaborative project; thus, status differences could emerge right away. Specifically, we used a task called Lost on the Moon, in which the group is told it has crash-landed on the moon and needs to get back to the mother ship using a list of 15 items (Robins \& Beer, 2001). In Week 2, we used a task that would facilitate personal disclosure and the development of interpersonal ties to mimic the same process that occurs in real-world groups. Specifically, group members engaged in an informal exercise where they asked each other a series of questions such as "What was your most embarrassing moment?" (adapted from Aron, Melinat, Aron, Vallone, \& Bator, 1997). In Week 3, we used a more competitive task to allow for conflicts to emerge, which is also a part of real-world group experiences. Specifically, groups role-played a university's alumni committee; the committee awarded prize money to deserving alumni, and each group member was asked to advocate for a specific nominee (adapted from John \& Robins, 1994). Finally, in Week 4, we used a fun task to help alleviate any potential tension left over from the competitive task in Week 3 and to provide more variability in the tasks in which groups engaged. Group members played the board game Beyond Balderdash (Gameworks Creations, 1995), in which they tried to guess the correct definitions of various words from a list of potential definitions. ${ }^{5}$

\section{Measures}

Self-perceived and actual status. After each of the four group meetings, each participant privately rated the status of every other group member by indicating agreement with the item "This person had a lot of status within the group today" on a scale from 0 (Disagree very strongly) to 10 (Agree very strongly). They also rated their own status with the item "I had a lot of status within the group today," using the same response scale. We used the software program SOREMO (Kenny, 1995) to implement the social relations model analyses of the round-robin (i.e., peer) status ratings. For each of the four sessions, SOREMO calculated two scores for each participant: a target score, which is an index of how that individual was typically perceived by the others in the group, and a perceiver score, which is an index of how the individual typically perceived others. SOREMO removed group differences, making target and perceiver scores statistically independent of group membership and thus appropriate for conventional least squares procedures that assume independence (see Kenny \& La Voie, 1984). Target scores for status showed statistically significant amounts of variance in all 4 weeks (relative variances were $.40, .20, .34$, and .19 , respectively), indicating group members agreed about one another's status at better than chance levels in all 4 weeks. The extent of agreement on status differed across weeks; pairwise comparisons of consensus between different weeks indicated that all weeks differed from each other, with the exception of Weeks 2 and 4 .

Status self-enhancement. The social relations model design allowed us to utilize the index of self-enhancement recently developed by Kwan and colleagues (Kwan, John, Kenny, Bond, \& Robins, 2004). Selfenhancement has been operationalized in different ways in the literature. Some studies have used a self-insight approach, in which an individual's self-perceptions are compared with peers' perceptions of the individual; for example, if an individual believes himself or herself to be more intelligent than others believe him or her to be, this is considered evidence of self-enhancement. Other studies have used a social comparison approach, in which an individual's self-perceptions are compared with that individual's perceptions of others; for example, if an individual believes himself or herself to be an above-average driver, this is considered evidence of self-enhancement. The Kwan index, based on the social relations model, represents a conceptual and methodological breakthrough because it integrates both approaches and corrects biases present in each, providing a measure of self-enhancement with fewer confounds (Kwan et al., 2004).

To examine the consequences of status self-enhancement, we calculated a self-enhancement index for status based on the technique described by Kwan et al. (2004). In this technique, status self-enhancement is calculated as

${ }^{5}$ Srivastava and Beer (2005) reported an investigation of selfperceptions and target ratings of acceptance in this same data set. That investigation did not include any analyses of status. 


$$
\mathrm{SE}=\mathrm{S}-\mathrm{T}-\mathrm{P}-\mathrm{G},
$$

where SE is self-enhancement, $\mathrm{S}$ is the self-perception, $\mathrm{T}$ is the (groupmean-deviated) target score, $\mathrm{P}$ is the (group-mean-deviated) perceiver score, and $\mathrm{G}$ is the group mean. ${ }^{6}$ The self-insight approach is represented by the subtraction of target scores (which index how an individual is viewed by others), and the social-comparison approach is represented by the subtraction of perceiver scores (which index how an individual views others). Subtraction of the group mean scales the self-enhancement score so that the zero point indicates an unbiased self-perception; the group subtraction also makes self-enhancement scores statistically independent of group membership.

Self-perceived and actual social acceptance. Participants rated the other members of their group on the item "I like this person" on a scale from 0 (Disagree very strongly) to 10 (Agree very strongly). Participants were also asked to rate themselves on the item "I am a likable person" in the context of the group setting, using the same 0 to 10 scale. We used SOREMO (Kenny, 1995) to implement the social relations model analyses of the round-robin acceptance ratings and operationalized social acceptance as the target score (i.e., the group's collective judgment of how much they liked an individual). Target scores for social acceptance showed lower relative variances than did target scores for status, though in all weeks except the last, the target variances were significant (relative variances were $.06, .07, .06$, and .02 , respectively).

\section{Results and Discussion}

\section{Hypothesis 1: Group Members Who Engage in Status Self-Enhancement Will Be Less Accepted by Other Members Than Those Who Perceive Their Status Accurately}

Because our design assessed individuals over time, we analyzed the data using hierarchical linear modeling (Bryk \& Raudenbush, 1992) with cross-lagged effects. Each of the individuals in the study had four status self-enhancement scores and four acceptance scores from each of the 4 weeks of the study. At Level 1, we modeled how an individual's acceptance varied over time as a function of the individual's prior status self-enhancement (STATUS_SE), controlling for the individual's prior acceptance (ACCEPTANCE) to account for autocorrelations in acceptance. Thus, we specified the following equation at Level 1 to model within-person effects:

$$
\begin{aligned}
& \operatorname{ACCEPTANCE}_{(t)}=b_{0}+b_{1} \times \operatorname{ACCEPTANCE}_{(t-1)} \\
& +b_{2} \times S T A T U S \_S E_{(t-1)} \text {. }
\end{aligned}
$$

Level 2 of the model aggregated the individual effects to yield a samplewide estimate and $t$ test of each of the coefficients, including the effect of status self-enhancement on acceptance $\left(b_{2}\right)$. A random effect on the intercept at Level 2 also accounted for variance in acceptance attributable to individual differences. (Because the social relations model indices remove any group-level dependence in the data, any Level 3 effects-i.e., between-groups effects-would be predetermined to be zero. However, for completeness, we also included a Level 3 random effect on the intercept so that our software would calculate the correct degrees of freedom.)

In this model, the key test of the hypothesis is the lagged effect of status self-enhancement on actual acceptance $\left(b_{2}\right)$. The results of the analysis, shown at the top of Table 1, indicate that over and above any influence of prior acceptance, status self-enhancement predicted lower levels of acceptance over time $\left(b_{2}=-.020, S E=\right.$ $.001, p<.05)$. That is, over and above the substantial stability in individuals' acceptance across the 4 weeks, status selfenhancement still predicted subsequent decreases in acceptance. In follow-up analyses, we included sex as a moderator variable; a null result indicated there was no significant difference in the magnitude or direction of the status self-enhancement effect between men and women. Simple within-week correlations were consistent with these lagged effects, showing a consistent negative relationship within week between status self-enhancement and acceptance (average $r=-.13$ across weeks).

In a model that added a quadratic term for status selfenhancement, we did not find evidence for a curvilinear relation between status self-enhancement and acceptance $\left(b_{3}=.000, S E=\right.$ $.002, p=.91)$. Thus, it appears that individuals who status selfenhanced were liked and accepted by fellow group members less than accurate self-perceivers, who in turn were liked and accepted less than self-effacers.

\section{Hypothesis 2: Face-to-Face Group Members Will Perceive Their Own Status Accurately}

Elevation accuracy. Examining elevation accuracy involved comparing mean levels of status self-perceptions with mean levels of peer perceptions (Cronbach, 1955). If individuals' selfperceptions of status were not significantly different from peer perceptions, they would be exhibiting elevation accuracy; if selfperceptions were higher, they would be exhibiting selfenhancement. Our primary interest was to compare status selfperceptions with peer-rated (i.e., actual) status; however, to provide context for that analysis, we also included comparisons between self-reported social acceptance and peer-rated social acceptance.

Because elevation accuracy concerns the actual means of selfand peer ratings, we did not use the SOREMO target effects, which are mean centered; rather, we analyzed the raw scores for self- and peer ratings. Because the raw scores were dependent on group membership, we conducted the analysis at the group (rather than the individual) level to eliminate any dependence in the data, by averaging self- and peer ratings for each group (Kenny, 1996). In addition to making comparisons between status and social acceptance, we also included factors to account for effects of week and of sex composition of the groups (i.e., operationalized as the proportion of men in the group). Thus, the analysis was a four-way $(2 \times 2 \times 4 \times 10)$ mixed analysis of variance (ANOVA) at the group level with three within-groups factors (self- vs. peer percep-

\footnotetext{
${ }^{6}$ One can measure self-enhancement by constructing a discrepancy score, in which peers' perceptions are subtracted from self-perceptions, or by partialing out peers' perceptions from self-perceptions in the regression analyses. Each method has advantages and disadvantages. The discrepancy-score method can confound the effects of self- and peer perceptions (e.g., self-esteem might correlate with a discrepancy score only because it correlates with self-perceptions, not because it correlates negatively with peer perceptions). However, partialing out peer perceptions can create problems of multicollinearity, leading to unstable estimates. We followed Kwan et al.'s (2004) approach and used discrepancy scores.
} 
Table 1

Multilevel Models Predicting Social Acceptance and Status Self-Enhancement in Study 1

\begin{tabular}{lrrr}
\hline \multicolumn{1}{c}{ Parameter } & $\begin{array}{c}\text { Unstandardized } \\
\text { coefficient }\end{array}$ & $S E$ & $t$ test \\
\hline DV: Social acceptance & & & \\
$\quad$ Lag-1 acceptance $\left(b_{1}\right)$ & 0.611 & 0.034 & $17.70^{* * *}$ \\
Lag-1 status self-enhancement $\left(b_{2}\right)$ & -0.020 & 0.009 & $-2.36^{*}$ \\
DV: Status self-enhancement & & & \\
Lag-1 status self-enhancement $\left(b_{1}\right)$ & 0.130 & 0.041 & $3.16^{*}$ \\
Lag-1 acceptance $\left(b_{2}\right)$ & -0.262 & 0.173 & -1.51 \\
\hline
\end{tabular}

Note. $N=152 . \mathrm{DV}=$ dependent variable.

${ }^{*} p<.05 . \quad{ }^{* * *} p<.01$.

tions, status vs. acceptance, and week) and one between-groups factor (the sex composition of the group).

Table 2 presents self- and peer ratings for status and acceptance across all 4 weeks; statistics (including standard deviations) are presented at the group level because that is how we conducted the analysis. There was not a significant main effect for self- versus peer perception at the group level, $F(1,18)=1.64, n s$, indicating that there was not support for a general self-enhancement effect across both status and acceptance. However, consistent with expectations, there was a significant interaction between source of rating (self vs. peer) and type of rating (status vs. acceptance), $F(1$, $18)=39.20, p<.01$. A planned comparison showed that selfratings of acceptance were significantly higher than peers' social acceptance ratings, $F(1,27)=39.07, p<.01$. Self-ratings of status were, however, significantly lower than peers' status ratings, $F(1,27)=18.69, p<.01$. Thus, although people showed a self-enhancement bias in perceiving their acceptance, they showed a bias toward self-effacement in perceiving their status. There was not a significant effect for the groups' sex composition on perceptions of status or acceptance, nor were there any interactions involving group sex composition.

The self-effacement effect in perceiving status was not moderated by week, $F(1,25)=1.80$, ns. There was, however, a significant moderating effect of week on how much individuals selfenhanced when perceiving their acceptance, $F(1,25)=11.19, p<$ .01. Specifically, self-rated acceptance exceeded social acceptance

Table 2

Elevation Accuracy: Self- and Peer Ratings of Status and Acceptance Across 4 Weeks in Study 1

\begin{tabular}{cccccc}
\hline & \multicolumn{2}{c}{ Status } & & \multicolumn{2}{c}{ Acceptance } \\
\cline { 2 - 3 } \cline { 5 - 6 } Week & Self-perception & Peer rating & & Self-perception & Peer rating \\
\hline 1 & $5.06(0.91)$ & $5.37(0.52)$ & & $7.13(0.95)$ & $5.72(0.58)$ \\
2 & $5.05(0.72)$ & $5.75(0.54)$ & & $7.39(0.92)$ & $6.74(0.58)$ \\
3 & $5.42(0.75)$ & $5.98(0.50)$ & & $7.36(0.89)$ & $6.68(0.60)$ \\
4 & $5.36(1.04)$ & $5.80(0.74)$ & & $7.59(0.74)$ & $6.90(0.61)$ \\
\hline
\end{tabular}

Note. Between-groups standard deviations are in parentheses. We consider peer ratings of status and acceptance to reflect the person's actual status and acceptance, respectively. Self-perceptions of status are significantly lower than peer ratings across weeks. Self-perceptions of acceptance are significantly higher than peer ratings across weeks. much more in Week 1 (a difference of 1.39) than in the other three weeks (differences of $0.66,0.65$, and 0.70 , respectively). People might have self-enhanced when perceiving their acceptance particularly in Week 1 because it was the beginning of the group's development, and thus, individuals did not have as much information to inform their judgments; as self-perceptions of acceptance are not constrained in the same way as status, there was more opportunity for self-enhancement tendencies to emerge.

Differential accuracy: Correlations between self- and peer ratings. Examining differential accuracy involved correlating selfperceptions of status with peer perceptions (Cronbach, 1955). If individuals' self-perceptions of status were to correlate highly with peer perceptions, they would be exhibiting differential accuracy. For these analyses, carried out on the individual-level data, we used target scores as the measure of peer perceptions and selfratings as a measure of self-perceptions. Because the self-ratings were potentially dependent on group membership, we followed Kenny, Kashy, and Cooks (2006) recommendation and computed partial correlations between self-ratings and target scores, with group effects partialed out by using 27 dummy variables representing membership in the 28 groups.

Shown in Table 3 are the self-peer partial correlations for status and acceptance across the 4 weeks. As shown, self-peer agreement was high for status, indicating that individuals were significantly accurate in perceiving their status. Partial correlations of accuracy were as high as .59 and were, on average, .46 across weeks. It is interesting to note that status accuracy was lowest in Week 2, in which group members engaged in the get-acquainted task. It might have been more difficult for individuals to assess their status in such an informal exercise that had no explicit goal. We tested for sex differences in individuals' accuracy in perceiving their status using moderated multiple regression analyses (Aiken \& West, 1991) with group dummy variables entered as controls and found no significant or substantial differences in any of the 4 weeks.

Self-rated acceptance correlated somewhat with peer-rated social acceptance; all self-peer partial correlations were significant and averaged .20 across the 4 weeks. These partial correlations were lower than the self-peer correlations for status perceptions; we tested the differences between them using Raghunathan, Rosenthal, and Rubin's (1996) method. Self-peer partial correlations were significantly higher for status than for acceptance in Week $1(Z=3.30, p<.01)$ and in Week $3(Z=2.28, p<.01)$.

Table 3

Differential Accuracy in Self-Perceptions of Status and Acceptance in Study 1

\begin{tabular}{ccc}
\hline & \multicolumn{2}{c}{ Accuracy correlation } \\
\cline { 2 - 3 } Week & Status & Acceptance \\
\hline 1 & $.59^{* * *}$ & $.16^{*}$ \\
2 & $.34^{* * *}$ & $.28^{* *}$ \\
3 & $.48^{* *}$ & $.16^{* *}$ \\
4 & $.42^{* * *}$ & $.21^{* *}$ \\
\hline
\end{tabular}

Note. Shown are partial correlations between self-perceptions and target effects (or peer ratings), with group membership partialed out through dummy variables. Accuracy partial correlations for status are significantly higher than accuracy partial correlations for acceptance in Weeks 1 and 3. ${ }^{*} p<.05 .{ }^{* *} p<.01$ 
The correlations were not significantly higher in Weeks 2 and 4, however. These self-peer partial correlations may have been lower because there was also lower peer-peer agreement on social acceptance (Kenny, 1994).

Differential accuracy: Comparing accuracy with consensus. Another way to create a context to interpret differential accuracy, which can be operationalized within Kenny and La Voie's (1984) social relations model, is to compare whether self-other covariance (i.e., differential accuracy) is as high as consensus variance (i.e., the agreement among different peers). If self-other agreement is about equal to consensus, this indicates that the average individual knows his or her own status as well as the average peer observer. Following Kenny's (1994) method, we conducted a two-factor $(2 \times 4)$ ANOVA on the group level, with self-peer covariance versus target variance as the first within-groups factor (which tested individuals' accuracy against peers' accuracy) and week as the second within-groups factor. Self-peer covariance was not significantly different from target variance, $F(1,17)=0.13$, $n s$. There was no main effect of agreement type, nor was there any interaction effect with week. Thus, this suggests individuals' perceptions of their status were as good an indicator of their actual status as any other group member's perception of their status.

Although we hesitate to overinterpret this null effect, it is interesting in light of the finding that on most dimensions of social perception, self-peer agreement is typically lower than peer-peer agreement (Kenny, 1994). Thus, on the basis of prior research, one would expect individuals' accuracy in viewing their status to be lower than peers' consensus in viewing the individual's status. The relative accuracy with which people perceived their status provides support for the idea that individuals are uniquely motivated to perceive their status accurately.

\section{Additional Questions}

Predicting status self-enhancement from acceptance. We found a lagged effect of status self-enhancement on social acceptance. Was the reverse direction also supported by the data? For example, did lower levels of acceptance predict higher levels of status self-enhancement over time? To evaluate this hypothesis, we specified a similar hierarchical linear model, this time with status self-enhancement as the dependent variable and with acceptance as a predictor:

$$
\begin{aligned}
\text { STATUS_SE } E_{(t)}=b_{0}+b_{1} \times S T A T U S \_S E_{(t-1)} \\
+b_{2} \times \operatorname{ACCEPTANCE} E_{(t-1)} .
\end{aligned}
$$

The results of this analysis are shown at the bottom of Table 1. There was no significant lagged effect of acceptance on status self-enhancement.

Is status self-enhancement a self-fulfilling prophecy? We also explored whether self-perceived status influenced individuals' actual status (i.e., their peer-rated status). We conducted a similar hierarchical linear model, this time with actual status as the dependent variable and self-perceived status, lagged by 1 week, as the predictor, with lagged actual status as a control. A significant lagged effect of self-perceived status, after controlling for prior levels of actual status, would indicate a self-fulfilling prophecy effect. ${ }^{7}$ The results of this analysis showed no predictive relation between self-perceived status and actual status $(b=0.02, S E=.020, p=.34)$. Further, follow-up analyses indicated this relation did not vary according to participants' sex. Therefore, the evidence does not indicate that engaging in status self-enhancement helped achieve higher status in the group or that it harmed one's status in the group.

\section{Summary}

Supporting our first main hypothesis, individuals who engaged in status self-enhancement were less accepted by the group. Using cross-lagged analyses, we found a directional effect of status self-enhancement on one's social acceptance but did not find a directional effect of social acceptance on status self-enhancement. Although these findings do not unequivocally establish causation, they do provide evidence consistent with the conclusion that status self-enhancement leads to being less socially accepted. We also found no support for a self-fulfilling effect of self-perceived status on actual status. Thus, these analyses are consistent with the notion that status self-enhancement has only social costs and no apparent social benefits.

That we found a linear, rather than curvilinear, effect of status self-enhancement on social acceptance suggests that status selfenhancers were less liked and accepted than were accurate status perceivers (as predicted) but also that accurate perceivers were less liked and accepted than status self-effacers. We hesitate to conclude that status self-effacers are indeed liked more than accurate status perceivers because of the statistical difficulty of testing nonlinear effects (McClelland \& Judd, 1993). Tests of curvilinear effects typically have low power, decreasing our chances of detecting such an effect. Therefore, we examined this issue again in Study 2 with a larger number of groups, which provided greater statistical power in a new sample.

Supporting our second main hypothesis, participants tended to perceive their status accurately relative to how they perceived their social acceptance. Not only did participants refrain from engaging in status self-enhancement (i.e., they did not overestimate their status) but also they tended to engage in status self-effacement, such that individuals' self-perceptions of status were consistently lower than their actual status. This suggests individuals might have been so concerned about their acceptance in the group that they were overly humble in perceiving their status. It also might suggest that individuals status self-effaced to further increase their social acceptance.

That individuals did engage in self-enhancement when perceiving their acceptance helps rule out a methodological concernnamely, that the accuracy we observed in self-perceptions of status might have been due to our methods or measures. Given that these same individuals in this same setting did engage in selfenhancement when perceiving their acceptance, we can be more assured that our accuracy findings are unique to status.

\footnotetext{
${ }^{7}$ In his reflection-construction model, Jussim (1991) pointed out that the beliefs that produce self-fulfilling prophecies can be based on initially valid information (which produces a special kind of self-fulfilling prophecy that he called the self-sustaining effect) as well as on biased or flawed beliefs. Thus, we used self-perceived status, rather than the self-enhancement index, as the predictor in this analysis.
} 


\section{Study 2}

We have argued that engaging in status self-enhancement has social repercussions (Hypothesis 1) and that these social repercussions lead people to keep their self-perceptions of status in check because people are concerned for acceptance and inclusion in social groups (Hypothesis 2). For Study 2, we expanded this idea into a third hypothesis - that the more an individual was concerned with social acceptance, the lower that individual's self-perceptions of status would be relative to his or her actual status (Hypothesis 3). To test this hypothesis, we directly measured individuals' concern for acceptance in a group.

We also examined how individual status self-enhancement affects the group as a whole. As we have argued, when group members view their status in an overly positive way, they are likely to violate peers' expectations of their behavior and provoke conflict. Therefore, we predicted that groups with members who self-enhanced would show evidence of greater levels of conflict while working on a task together (Hypothesis 4). That is, when group members' self-perceptions were higher on average than their peer-rated status, the group would exhibit more conflict. Furthermore, along a more exploratory vein, we examined whether average levels of status self-enhancement affected the group's task performance. If self-enhancement in status perceptions provoked conflict, this less harmonious group environment might hinder the group's effectiveness and efficiency and thus decrease their performance on tasks. Thus, we had groups perform tasks with easily measurable performance.

Examining group-level consequences also allowed us to further examine why status self-enhancement would damage individuals' acceptance in a group, whereas acceptance self-enhancement would not. We have argued that status self-enhancement decreases social acceptance because it instigates intragroup conflict; however, acceptance self-enhancement does not damage individuals' actual acceptance because it does not have any effect on the group's stability and does not provoke intragroup conflict. We tested this assertion directly in Study 2 by examining the relation between self-enhancement in perceptions of acceptance and intragroup conflict.

Finally, to better understand the mechanisms underlying accuracy, we used a more multifaceted measure of status in Study 2, which allowed us to differentiate several components of status. One potential alternative explanation for the accuracy we have observed in status perceptions is that status is a relatively clear and unambiguous dimension, precluding individuals from distorting their self-perceptions. That is, ambiguous dimensions can describe a wide variety of behaviors and thus allow people to use selfserving definitions when providing self-evaluations; however, unambiguous dimensions are more objective, are more precisely defined, and thus promote more accurate self-perceptions. Previous studies have found that individuals engage in selfenhancement more on ambiguous dimensions (e.g., moral, sophisticated, and sensible) than on unambiguous dimensions (e.g., intelligent, athletic, and punctual; Allison, Messick, \& Goethals, 1989; Dunning et al., 1989).

If the unambiguous nature of status were responsible for the accuracy we have observed, we would expect that individuals in Study 2 would be more accurate (for both elevation and differential accuracy) on the less ambiguous aspects of status than on perceiving the more ambiguous aspects and that, in terms of elevation accuracy, individ- uals would be more self-enhancing on the ambiguous aspects of status than on the unambiguous aspects of status.

\section{Method}

\section{Participants}

Participants were 432 undergraduate students ( 211 men, 221 women) at a West Coast university. They were 20 years old on average $(S D=2.88$ years). Participants were assigned to experimental sessions through a combination of volunteer sign-ups and phone calls inviting them to participate in return for course credit; participants were again assigned to groups in which they did not know other group members. The percentage of men in each group ranged from $0 \%$ to $100 \%$; on average, the percentage of men in each group was $50 \%$.

\section{Procedure}

Participants worked together in 4-person groups on problems randomly selected from previous versions of the Graduate Management Aptitude Test (GMAT), a test used primarily for selection into graduate schools of business. They were given 40 minutes to work together on as many problems as possible. Groups reported their answers on a single form, and experimenters explicitly instructed participants to work together as a group. They were told that the highest performing group experimentwide would receive $\$ 100$. Their performance would be coded similar to how it would be scored on similar standardized tests, in that they would be rewarded for correct answers and penalized for wrong answers. The total number of items answered correctly on average was $33.64(S D=11.99)$; the proportion of items answered correctly was $.81(S D=.10)$. Following the group task, participants privately completed a questionnaire.

\section{Measures}

Status. Individuals rated all 4 members of their group, including themselves, on seven status-related items: how much each person received respect from other group members, made valuable contributions, demonstrated high ability, influenced group decisions, led the group's activities, participated, and contributed to the group overall. Each item was rated on a scale from 1 (Not at all) to 7 (A great deal).

Using the software program SOREMO (Kenny, 1995), we computed the target scores for each of the seven status ratings, which is essentially their peer-rated average for those ratings. We then computed an alpha reliability (internal consistency) of the seven peer-rated indices that constituted our status measure. The peer-rated indices had an alpha of .95, indicating high reliability of the status measure. Furthermore, there were significant amounts of peer-rated variance at the $p<.05$ level in all seven status indices $(M=.36)$, indicating that there was high peer consensus as to who was high and who was low in status (Kenny, 1994).

Status self-enhancement. For analyses examining the consequences of self-enhancement, we again calculated a self-enhancement index for status based on Kwan et al.'s (2004) technique. We averaged the seven status self-enhancement indices to form an overall score $(\alpha=.87)$. The social relations model calculations remove any group-level dependence in the data.

Social acceptance. Individuals rated the other members of their group on five dimensions chosen to be relevant to the context of Study 2: how much they would want to work with the target again, how much the target had earned their trust as a coworker, how similar they felt to the target, how much in common they felt they had with the target, and how different they seemed from the target (reverse-scored). They also rated how much their fellow team members would want to work with them again, how much they had earned their fellow team members' trust, and so on. Each item was rated on the same scale, from 1 (Not at all) to 7 (A great deal). We used these items to measure social acceptance because the experiment was 
presented to participants as a simulation of work in organizations; thus, for example, rating their desire to work together in the future seemed more appropriate than rating their likeability.

We used SOREMO to compute the peer-rated (or target) effects of the five social acceptance ratings. There were significant amounts of variance for only two of the five peer-rated indices: how much they would want to work with the target again and how much the target had earned their trust $(M=0.06)$. Thus, we used those two indices to measure social acceptance $(\alpha=.81)$. Again, the social relations model indices removed any grouplevel dependence in the data.

Acceptance self-enhancement. We calculated a self-enhancement index for acceptance by computing Kwan et al.'s (2004) index from an average of the acceptance ratings $(\alpha=.69)$. The acceptance selfenhancement index correlated significantly but not highly with the status self-enhancement index, $r(432)=.28, p<.01$. This suggests that individuals who perceived their status in an overly positive way were slightly more likely to perceive their social acceptance in an overly positive way but that these two forms of self-enhancement were also somewhat distinct.

Intragroup conflict. Individuals rated on a scale from 1 (Not at all) to 7 (Extremely) how much conflict their group experienced with the item "To what extent did group members disagree over the task solutions during the group task?" (intraclass correlation $=.60, p<.01$ ). These ratings were aggregated within group $(M=2.78, S D=.78)$.

Concern for social acceptance. Individuals rated two items, "How aware were you that you were being evaluated by the other group members?" and "How worried were you about saying/doing the wrong thing?", on a scale from 1 (Not at all) to 7 (Extremely). These items were combined to form one measure of concern for social acceptance $(\alpha=.61)$. After controlling for group effects, $M=0.00, S D=1.21$.

Ambiguity of status dimensions. Eight independent judges rated the seven dimensions of status on how ambiguous versus unambiguous they are. Specifically, the judges were told that in a recent study, groups of 4 people worked on GMAT problems together and that following the task, each group member was asked to rate all group members on these seven dimensions. We asked the judges to imagine themselves making these ratings and to gauge the ambiguity or lack of ambiguity of each dimension using a scale from 1 (Very ambiguous, less objective) to 7 (Very unambiguous, more objective). The raters agreed highly on which dimensions were more or less ambiguous $(\alpha=.86)$. We created self- and peer-rated scores for each individual on the status dimensions rated as more ambiguous (i.e., received respect from other group members, influenced group decisions, and demonstrated high ability; average score $=4.20$ ) and those rated as less ambiguous (i.e., participated, made valuable contributions, led the group's activities, and contributed to the group overall; average score $=5.43$ )

\section{Results and Discussion}

\section{Hypothesis 1: Group Members Who Engage in Status Self-Enhancement Will Be Less Accepted by Other Members Than Those Who Perceive Their Status Accurately}

Although Study 2 did not have a longitudinal structure and, thus, we could not test for lagged effects, we were able to test for crosssectional associations between status self-enhancement and social acceptance target scores. Both of these scores were independent of group effects and thus appropriate for regression analyses. As expected, individuals who engaged in status self-enhancement were less socially accepted $(\beta=-.25, p<.01$; unstandardized $B=-.24$, $S E=.04)$. This effect is illustrated in Figure 1. Moderated multiple regression analysis indicated no interaction with sex, suggesting that this effect was equally strong for both men and women. Also, similar to Study 1, there was no evidence of a curvilinear relation between status self-enhancement and acceptance. In a model that added a quadratic term for status self-enhancement, we did not find evidence for a curvilinear relation between status self-enhancement and acceptance ( $b=.004, S E=.098, p=.968)$. Thus, status self-effacers were liked more than accurate status perceivers, who in turn were liked more than status self-enhancers.

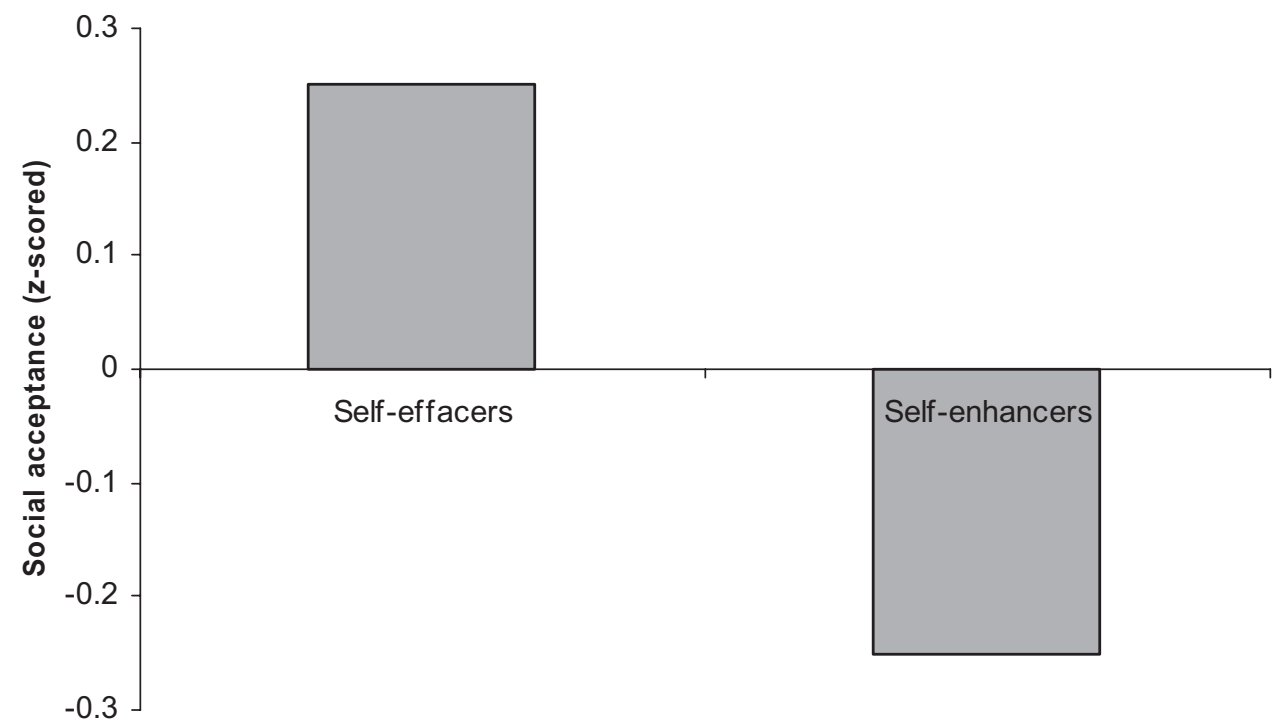

Figure 1. Study 2: The social consequences of status self-enhancement. For illustrative purposes, presented are average levels of acceptance for status self-enhancers, or individuals whose self-perceived status was higher than their actual (or peer-rated) status, and for status self-effacers, or individuals whose self-perceived status was lower than their actual status. No individuals perceived their status with perfect accuracy. We used regression analyses to test the significance of the effect of status self-enhancement on social acceptance. 


\section{Hypothesis 2: Face-to-Face Group Members Will Perceive Their Own Status Accurately}

Elevation accuracy. To examine elevation accuracy, we ran a three-factor $(2 \times 2 \times 5)$ ANOVA at the group level, similar to Study 1 ; the three factors were self- versus peer perceptions, status versus acceptance perceptions, and the sex composition of the group (all male, majority male, balanced, majority female, and all female). This analysis revealed a main effect for self- versus peer perception, $F(1,103)=72.32, p<.01$, indicating a general self-enhancement effect across perceptions of status and acceptance. However, consistent with expectations, there was also a significant interaction in that this self-enhancement effect was moderated by status versus acceptance perceptions, $F(1,103)=$ $111.25, p<.01$.

As illustrated in Table 4, participants overestimated their social acceptance on average, $F(1,103)=128.06, p<.01$, consistent with Study 1 . However, participants again underestimated their status on average, $F(1,103)=3.14, p<.05$. This indicates, again, that individuals self-enhanced in perceiving their acceptance but self-effaced in perceiving their status. The groups' sex composition was not related to perceptions of status or social acceptance, nor did any interactions involving group sex composition emerge.

Differential accuracy: Correlations between self- and peer perceptions. To examine differential accuracy, we followed Kenny et al. (2006) and correlated self-perceived status with actual (peerrated) status, while partialing the group effects with 107 dummy variables to represent membership in the 108 groups. Consistent with Study 1, participants showed high differential accuracy in perceiving their status. The relation between self-perceptions of status and peer-rated status was substantial (partial $r=.626, p<$ $.01)$. The self-peer correlation for social acceptance was also significant, but lower (partial $r=.155, p<.01$ ). We tested whether accuracy was significantly higher for perceptions of status than for perceptions of acceptance by using Raghunathan et al.'s (1996) method. As expected, individuals were more accurate in perceiving their status than their acceptance $(Z=4.45, p<.01)$. We found no sex difference in individuals' accuracy in perceiving their status or acceptance in moderated multiple regression analyses (Aiken \& West, 1991).

Differential accuracy: Comparing accuracy and consensus. Also consistent with Study 1, individuals were as accurate in perceiving their own status as peers were in perceiving that individual's status. That is, self-peer agreement (covariance $M=.65$, $S D=.97$ ) was not significantly different from peer-peer agree-

Table 4

Elevation Accuracy: Self- and Peer Ratings of Status and Social Acceptance in Study 2

\begin{tabular}{lcc}
\hline \multicolumn{1}{c}{ Dimension } & Self-perception & Peer rating \\
\hline Status & $5.30(0.58)$ & $5.40(0.45)$ \\
Social acceptance & $5.96(0.57)$ & $5.01(0.73)$ \\
\hline
\end{tabular}

Note. Standard deviations are in parentheses. We consider peer ratings of status and acceptance to reflect the person's actual status and acceptance, respectively. Self-perceptions of status are significantly lower than peer ratings. Self-perceptions of acceptance are significantly higher than peer ratings. ment (target variance $M=.65, S D=.85), F(1,107)=0.00, n s$. This indicates that individuals' perceptions of their status were as close to their actual status as any other group member's perception of their status.

Was accuracy in self-perceptions of status due to the unambiguous nature of status? Prior research has found that individuals self-enhance more on dimensions that are relatively ambiguous than on those that are less ambiguous. To examine whether this pattern emerged in different dimensions of status, we ran a twofactor $(2 \times 2)$ within-subjects ANOVA at the group level with self- versus peer perceptions and unambiguous versus ambiguous status dimensions as the two within-subjects factors. This analysis revealed a main effect for self- versus peer perception, $F(1,107)=$ $7.50, p<.01$, again indicating an overall self-effacement effect in status perceptions. It also revealed a main effect for the ambiguity of the status dimension, $F(1,107)=24.31, p<.01$, indicating higher self- and peer ratings for the unambiguous dimensions. However, there was not a significant interaction, in that individuals were equally self-effacing on both the more ambiguous dimensions (self-rating $M=5.22, S D=.62$, compared with peer rating $M=5.34, S D=.48$ ) and the less ambiguous status dimensions (self-rating $M=5.36, S D=.59$, compared with peer rating $M=$ $5.45, S D=.45), F(1,107)=1.92, p=.17$. In fact, the direction of the effect was such that individuals were more self-effacing on the more ambiguous dimensions than on the less ambiguous dimensions (not vice versa).

In terms of differential accuracy, we found that accuracy was high for the more ambiguous dimensions of status (partial $r=$ $.535, p<.01$ ), as well as for the less ambiguous, more concrete dimensions of status (partial $r=.646, p<.01$ ). Therefore, although the lack of ambiguity in some dimensions of status might have helped boost the accuracy with which individuals perceived their status, individuals were still substantially accurate in viewing the more ambiguous dimensions of status.

\section{Hypothesis 3: Individuals' Concern for Social Acceptance Keeps Their Self-Perceptions of Status in Check}

The concern for acceptance in the group was related negatively to status self-enhancement $(\beta=-.08$; unstandardized $B=-.06$, $S E=.03$ ), a hypothesized effect that was significant at $p<.05$ by a one-tailed test (two-tailed $p=.07$ ). Thus, although individuals on average engaged in status self-effacement, individuals more concerned about being socially accepted were especially likely to do so. This finding supports the idea that the fear of being less socially accepted attenuates self-enhancement tendencies in perceiving one's status and even leads people to self-efface.

\section{Hypothesis 4: Status Self-Enhancement Instigates Conflict in the Group}

The more individual group members engaged in status selfenhancement, the higher the level of conflict there was in the group as a whole. On the group level, the correlation between average status self-enhancement levels in groups and intragroup conflict was $r(108)=.23, p<.01$. We illustrate this relation in Figure 2, categorizing groups as self-enhancing if the average self-rating in the group was higher than the average peer rating in the group or as self-effacing if the average self-rating in the group was lower 
than the average peer rating in the group. As shown, groups whose members self-enhanced on average $(n=46)$ engaged in more conflict than did groups whose members self-effaced on average $(n=60)$.

On an exploratory level, we next examined whether the relation between status self-enhancement and intragroup conflict was mediated by lower levels of interpersonal liking. That is, did groups whose members engage in status self-enhancement experience more conflict because they liked each other less? Mediation analyses did not support this account. When controlling for average levels of liking in groups, the relation between status selfenhancement and group conflict was not significantly reduced, Sobel test $t(108)=-.359, p=.719$. Thus, the effect of status self-enhancement on intragroup conflict was not mediated by lower levels of interpersonal liking.

Intragroup conflict was also related to lower group performance, $r(82)=-.31, p<.01$, suggesting the more a group engaged in conflict, the worse it performed. However, there was not a significant direct relation between a group's average levels of status self-enhancement and its performance; the direct correlation between average levels of status self-enhancement and group performance was $r(82)=-.10$, ns. Because groups' performance was measured as a proportion of correct to incorrect answers, we then looked separately at the raw number of problems answered correctly and the number of problems answered incorrectly. This analysis provided an intriguing picture: Groups whose members exhibited more status self-enhancement answered more problems correctly, $r(82)=.24, p<.05$, but also answered more problems incorrectly, $r(82)=.16, p=.08$, though the latter correlation was marginally significant. Therefore, these findings depict groups with more status self-enhancers as producing more, but not always accurate, answers.

Finally, we found that self-enhancement in perceptions of social acceptance was not related to intragroup conflict, $r(108)=.08, n s$. This supports our argument that self-enhancement in perceiving one's social acceptance does not damage individuals' actual acceptance because it does not provoke conflict. When group members perceived how much they were trusted and accepted in an overly positive way, this did not seem to disrupt the group's harmony.

\section{Summary}

The findings from Study 2 are highly consistent with those from Study 1. Individuals were accurate in perceiving their status and even self-effaced; at the same time, they perceived their social acceptance in an overly positive way. Furthermore, self-enhancers were again less likely to be socially accepted by other members of their group.

The findings from Study 2 also extend our previous results. First, individuals who were more concerned about their acceptance in the group were less likely to engage in status self-enhancement This lends further support to the idea that the need to belong helps keep individuals' perceptions of their status in check. Second, groups with more status self-enhancers engaged in more conflict, and this conflict, in turn, was related to lower group performance, providing some insight into why self-peer agreement in status perceptions is so important: Group members who agree on their status cohere better as a group, whereas those who disagree instigate more conflict and disruptions. Furthermore, we did not find a

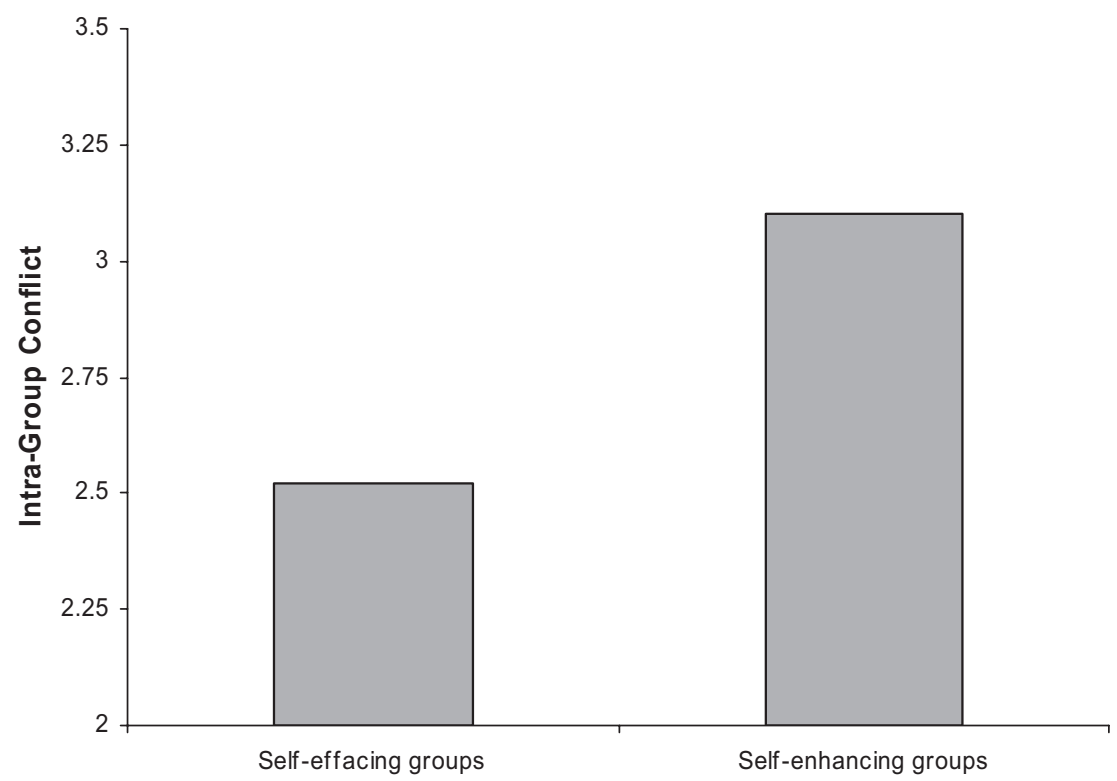

Figure 2. Study 2: Status self-enhancement and intragroup conflict. For illustrative purposes, presented are intragroup conflict levels for self-enhancing groups, or groups whose members' self-perceived status was higher on average than their actual (or peer-rated status), and for self-effacing groups, or groups whose members' self-perceived status was lower on average than their actual status. In no groups were self-perceptions of status exactly equal to peer perceptions. We used regression analyses to test the significance of the effect of status self-enhancement on intragroup conflict. 
significant relation between acceptance self-enhancement and group conflict; though, again, we hesitate to make too much of a null finding, considered along with our other findings it is consistent with the idea that individuals are freer to engage in acceptance self-enhancement because this form of self-enhancement does not disrupt group functioning. Finally, we found that individuals were accurate and self-effacing on both ambiguous and less ambiguous elements of status, which helps rule out the alternative explanation that the accuracy with which individuals perceive their status is simply due to its unambiguous nature.

\section{General Discussion}

\section{Accuracy in Self-Perceptions of Status}

In two studies, one of which included four separate group assessments, we found consistent evidence that people generally did not engage in status self-enhancement but instead perceived their status with considerable accuracy. Self-peer correlations were high, on average .50, across all group assessments.

It is notable that self-perceptions of status were accurate even in groups of relative strangers that collaborated for short periods of time-as little as 20 minutes. Furthermore, self-perceptions of status were consistently accurate across group tasks-whether groups members worked collaboratively, competed with each other for scarce resources, or even did not have any clear taskrelated goal (as in the informal discussion groups in Week 2 of Study 1). Men and women were also equally accurate in perceiving their status in that there was not a single sex difference in any of our assessments. Finally, individuals were accurate in perceiving the more ambiguous elements of status (e.g., how respected they were) as well as the less ambiguous elements of status (e.g., how much they participated). Taken together, the current findings suggest that accuracy in self-perceptions of status emerges quickly in various kinds of group settings, among individuals of both sexes, and on diverse components of status.

Our studies also provide insight as to why individuals are accurate rather than self-enhancing in perceiving their status, even though status self-enhancement might boost self-esteem (e.g., Barkow, 1975): When group members engaged in status selfenhancement, they were less socially accepted-they were less liked, viewed as less enjoyable to be around, not as preferred as future work partners, and less trusted by others. The concern over maintaining belongingness in groups thus might be a driving factor in keeping individuals from forming overly positive perceptions of their status. In support of this explanation, we found a relation in Study 2 between humility in status perceptions and the concern for social acceptance: the more people cared about their membership in their group, the less likely they were to status self-enhance.

Along a more speculative vein, might there be evolutionary origins for the tendency to accurately view one's status? Throughout human evolutionary history, people have lived in face-to-face groups because social living provides survival and reproduction advantages over living in isolation (e.g., Baumeister and Leary, 1995; Buss \& Kenrick, 1998; Cosmides, Tooby, \& Barkow, 1992); those who maintained positive inclusion and acceptance in faceto-face groups were more likely to survive and pass on their genes to the next generation. Status hierarchies are thought to have been part of human social groups throughout evolutionary history (e.g.,
Buss, 1999; Wright, 1994). Therefore, humans might have evolved an acute sensitivity to hierarchical dynamics in face-to-face groups, including the tendency to view their status highly accurately-given the costs of inaccuracy, this sensitivity would help maintain inclusion and enjoy better reproductive success. In contrast, those who viewed their status in an overly positive light might have been rejected and ostracized and found it more difficult to survive and reproduce.

Of course, it is also important to consider the possibility that participants refrained from engaging in status self-enhancement because they had little motivation to exaggerate their status in the first place. Participants may have cared little about their status because these were temporary groups of strangers, not of their own choosing, that simply fulfilled a course requirement; engaging in status self-enhancement might have had little benefit for their self-esteem. Though this is possible, we do not believe this explanation accounts for our findings for two reasons. First, previous work has shown that even in temporary groups of strangers such as the ones we studied, individuals' status has a strong effect on their self-esteem (Leary et al., 2001). Thus, people seem to care about their status even in these laboratory-based, ad hoc groups. This is perhaps because participants are among their peers-colleagues from the same university, with whom they are implicitly comparing themselves throughout their entire enrollment.

Second, if participants cared little about these groups, we would expect low variance in their level of caring about their status in these groups and would not expect to be able to explain this variance. Yet we did find variance, and more importantly, we found the opposite of what would have been expected by a lack of engagement explanation: the more people cared about their membership in these groups, the less likely they were to engage in status self-enhancement. This suggests that participants who cared little about these laboratory groups were more likely to engage in more status self-enhancement rather than less.

It is also important to consider that all of our analyses were correlational in nature, and we could not rule out the possibility that the link between status self-enhancement and decreased social acceptance was driven by variables that we did not assess directly, such as personality traits. For example, rude, hostile people might tend to engage in status self-enhancement, and their generally pugnacious ways might also lead them to be disliked by others. It is important for future research to rule out this possibility using experimental designs or by measuring and controlling for variables, such as personality traits, that might play a role in this process.

Finally, our results were obtained using mostly participants from the United States. As these participants came from a relatively individualistic Western culture, our results might change if we examined individuals from Eastern cultures. For example, individuals from Eastern cultures might be even less likely to engage in status self-enhancement because there might be more severe social costs for violating group status hierarchies (Heine, Lehman, Markus, \& Kitayama, 1999).

\section{Status Self-Effacement}

When there were deviations from peer ratings, or biases in self-perceptions of status, self-perceptions of status were not higher on average than peer ratings in any of our assessments but 
in fact were lower than peer ratings in all assessments. That is, although individuals tended to be accurate in terms of differential accuracy, they also tended to be slightly effacing in terms of elevation accuracy. This indicates that not only did individuals refrain from engaging in status self-enhancement but also they tended to self-efface in perceiving their status.

One explanation for this finding is that the need to belong and be included is so strong that people overcompensate, perceptually at least, to ensure that they do not engage in what Ridgeway and Berger (1986) called status violations, for example, talking too much or asserting their opinions too forcefully. Individuals might tend to be so concerned about their belongingness that they err on the side of being overly humble. This notion is similar to an argument posed in politeness research. Many norms of politeness lead people to be overly humble, cautious, and deferential because this helps them avoid interpersonal conflict (Keltner \& Anderson, 2000). For example, it is common for individuals who accidentally bump into someone to apologize automatically, regardless of who may be at fault.

Another possibility is that there are additional social benefits to status self-effacement that motivate people to be overly humble. In both studies, we found a linear relation between self-perceptions of status and social acceptance in that status self-effacers were liked more than accurate status perceivers, who in turn were liked more than status self-enhancers. Obtaining significant curvilinear effects is notoriously difficult (McClelland \& Judd, 1993), and thus, the failure to obtain a curvilinear effect might have been due to a lack of statistical power. However, if status self-effacers are indeed more socially accepted than accurate status perceivers, people might self-efface to further increase their liking and acceptance.

With regard to this self-effacement effect, it is worth considering again whether our findings might be unique to the kinds of group contexts we studied. It might be the case that in these short-term groups of strangers, underestimating one's status does not lead to forgoing any meaningful social benefits. Thus, in these groups, the benefits of being overly humble (i.e., more acceptance and liking) might outweigh the loss of some status-related rewards (e.g., forgoing decision-making control or the ability to express one's ideas and opinions). In real-world groups in which individuals' status is associated with more valuable rewards, underestimating one's status may mean passing up on more meaningful benefits. For example, in organizational groups, individuals who do not take credit for their contributions might receive less monetary compensation and lose out on opportunities to increase their formal authority in the organization (Flynn, 2003).

Finally, some individuals might be less likely to perceive their status with such humility. For example, narcissists have a grandiose sense of self and entitlement as well as a preoccupation with success and demands for admiration (see Morf \& Rhodewalt, 2001, for a review). Narcissism has been linked to the tendency to self-enhance (Gosling, John, Craik, \& Robins, 1998; John \& Robins, 1994), which suggests that narcissists might be more likely to view their status in an overly positive, rather than overly humble, way.

\section{Self-Enhancement in Perceptions of Social Acceptance}

In contrast to the accuracy we observed in self-perceptions of status, people did exhibit self-enhancement biases in perceiving their social acceptance. Individuals tended to form self-enhanced perceptions of how likeable they were, how much others trusted them, and how much others preferred them as future coworkers. This finding is important in part because it indicates that there is nothing unique about our participants or about the methods we used that led people to be less self-enhancing in general. Rather, there is something unique about self-perceptions of status that led to such high accuracy and humility.

We believe individuals view their social acceptance in an overly positive way because doing so does not damage their actual acceptance in the same way as overestimating one's status; people are freer to form positive illusions of their acceptance to help boost their self-esteem. In support of this argument, we found no effects of acceptance self-enhancement on group conflict; thus, groups are likely less prone to punish acceptance self-enhancers by alienating and ostracizing them.

It is possible that acceptance self-enhancement has other negative social consequences we did not observe here. For example, if individuals overestimate their closeness with others, they may overestimate the likelihood of receiving political support when they need it. Such illusions of alliance might have severely detrimental consequences when, in times of political strife, individuals decide to take political risks or to engage in conflict with other individuals under the mistaken belief that they have the support of numerous friends and allies. Overestimating one's closeness to others might also lead individuals to ask others for favors under the assumption that others will gladly comply. As recent research suggests, asking for favors in this way might elicit enmity because others are likely to comply out of obligation and then later resent the favor request (Flynn \& Bohms, 2006).

A remaining question is why individuals would keep their selfperceptions of status in check if they can fool themselves into thinking they are socially accepted. In other words, why would individuals care about maintaining social acceptance if they can simply construct an overly positive self-perception of acceptance? It is important to point out that although participants did engage in acceptance selfenhancement, they were also significantly accurate in viewing their social acceptance. Therefore, we believe individuals still feel the sting when they are socially rejected (Leary et al., 2001), even if they do have a somewhat overinflated view of their acceptance.

\section{Why Is Status Self-Enhancement Socially Punished?}

Why would engaging in status self-enhancement decrease one's social acceptance in the first place? We have proposed three possible reasons: Status self-enhancement challenges the existing status order and provokes conflict and discord in groups, it is seen as an illegitimate claim for rewards, and it is threatening to others because it signals a sense of superiority. Our group-level findings from Study 2 provide support for at least the first explanation. We found that groups whose members engaged in status selfenhancement experienced more conflict, and in turn, this conflict was related to lower group performance. In essence, these groups seemed to have too many cooks in the kitchen, with too many people trying to make decisions for the group and too few people deferring to others. Groups might therefore punish individuals who engage in status self-enhancement because such self-enhancement provokes intragroup conflict and undermines group progress toward collective goals. This explanation is given further support by the lack of relation between self-enhancement in perceptions of acceptance and intragroup conflict. Group functioning did not 
seem to be hindered when individuals viewed their acceptance in an overly positive way. Thus, groups might not alienate individuals who view their acceptance in an overly positive way because these individuals do no harm to the group.

Future research should also examine the other two possible reasons why status self-enhancement is socially punished. Is status self-enhancement indeed seen as an illegitimate claim for rewards? Is it threatening to others because it signals a sense of superiority? In particular, evidence for this latter notion might provide broader insights as to why self-enhancement in general is sometimes linked with negative social outcomes (Paulhus, 1998) and other times linked with positive social outcomes (Taylor \& Brown, 1988). We have argued that status in face-to-face groups is a zero-sum commodity, typically treated as a rank-order variable by groups; therefore, when individuals status self-enhance and signal their higher status, they necessarily signal others' lower status. On a more general level, this idea implies that individuals incur social costs when they self-enhance on a dimension in which they directly compete with others-that is, when individuals' expressed superiority necessarily implies others' inferiority — but not when they self-enhance on noncompetitive dimensions. For example, if an individual on a tennis team is in competition with other members to be the top player on the team and forms an overly positive perception of his or her tennis abilities, this might lead to social rejection and ostracism on the team. If that same individual forms an overly positive perception on an unrelated dimension (e.g., the ability to play chess), however, this might have little to no effect on the individual's acceptance on the tennis team because the individual is not in competition with the other team members for chess-playing prowess.

The issue of why people are punished for engaging in status self-enhancement also prompts questions about who is most likely to reject and ostracize status self-enhancers. We can envision three possible scenarios: First, all group members might reject status self-enhancers. Second, only individuals higher in the status hierarchy might dislike and reject status self-enhancers because it is only those individuals whose authority is being subverted. Third, only those closest in the hierarchy to the status self-enhancers (i.e., those slightly lower or higher in the hierarchy than the status self-enhancers) might dislike and reject them because those are the individuals most directly competing for status with the status self-enhancers.

We explored these possibilities and did not find any evidence for the latter two hypotheses. Although our analyses are only suggestive and not definitive, status self-enhancers were not more likely to provoke rejection by those higher than them in the hierarchy or by those closest to them in the hierarchy; status self-enhancement seemed to provoke rejection by the group as a whole. For example, in Study 2, we ranked each group member according to his or her peer-rated status. Status self-enhancement did not lead to less liking by those ranked higher in the status hierarchy $(r=-.12)$ than those ranked lower in the status hierarchy $(r=-.12$; the lack of reliability due to fewer data points likely constrained the magnitude of each of these correlations). Status self-enhancement also did not instigate less liking by those immediately above or below in the status hierarchy $(r=-.13)$ than those two rankings away in the hierarchy $(r=-.11)$, or three rankings away in the hierarchy $(r=-.14)$.
Just as important as understanding why status self-enhancement would be socially punished, it is worth exploring why status self-effacement would be socially rewarded. Why might status self-effacers be liked and accepted more than accurate status perceivers? First, status self-effacers might signal a particularly high degree of selflessness or an extreme willingness to put the group's interests above their own (Ridgeway, 1982). Status selfeffacers essentially forgo the social rewards they are entitled to in the eyes of the group based on the contributions they make to the collective. Groups might thus be even more accepting of status self-effacers because of the sacrifices they make for the good of the group. Further, status self-effacers might make other group members feel good about themselves because they signal others' relative superiority. Inasmuch as status is a zero-sum commodity in groups (Bales, 1950), self-effacers' humble behavior might complement others and boost others' self-esteem.

\section{Would Status Self-Enhancement Ever Provide Social Benefits?}

Some theorists have argued that having an overly positive view of one's status is adaptive because it helps convince others that one has high status (e.g., Krebs \& Denton, 1997). Once convinced of an individual's lofty standing, others might begin treating the individual with more deference and respect, which would increase the individual's actual status. This notion is similar to the theorized rationale behind conspicuous consumption, wherein individuals purchase highly visible and expensive objects such as exotic cars or large houses (Frank, 1985). These purchases, it is thought, communicate one's high status to others, with the aim of gaining friends in a higher social bracket or having a wider choice of romantic partners.

Although we did not find evidence for a self-fulfilling prophecy in our studies (there were no increases in status over time when individuals engaged in status self-enhancement), we believe there is a way to reconcile Krebs and Denton's (1997) arguments with our findings. Specifically, we believe that status self-enhancement has social costs primarily within groups that have established clear status hierarchies. However, in situations where individuals are interacting with individuals outside their group or when the status order of a given group is not clear, it is possible that overly positive self-perceptions of status may have social benefits. For example, if an individual falsely conveys to people outside his or her organization that he or she has high status, those people may not react negatively because they are not aware of the individual's actual place within the organization. In fact, given their lack of information about the individual's actual place in the organization's hierarchy, they might believe the individual and thus provide him or her with the deference and respect the individual seeks.

Moreover, self-enhancement in status perceptions might benefit individuals in groups with no well-defined hierarchy. In group contexts, overly positive self-perception of status may have the effects that Krebs and Denton (1997) predicted; it might lead to actual increases in status because other group members would show that individual deference and respect. By doing so, they would give the individual opportunities to lead the group, which in turn could lead to actual increases in status (Berger et al., 1972). 


\section{Conclusion}

Perhaps the most important implication of our findings is that they present a significant boundary condition to the positive illusions perspective. As previous work has shown, individuals form overly positive perceptions of themselves across variety of dimensions to maintain their self-esteem. Because people's perceptions of their status lie at the core of their self-esteem, individuals would thus seem particularly likely to engage in status self-enhancement to maintain self-esteem (Barkow, 1975). However, we found that individuals did not engage in status self-enhancement but instead perceived and interpreted information about their status accurately, even if such information might potentially harm their self-esteem.

On a broader level, we believe the current findings reflect a tension between the need for self-esteem and the need to belong. Although individuals have a strong need to think positively about their attributes to maintain self-esteem, they have an even stronger need to socially belong (Baumeister \& Leary, 1995; Maslow, 1968). Many times, these two forces can work independently from each other; for example, an individual can believe he or she is a better driver than he or she actually is, and such a self-serving bias does not damage the individual's interpersonal relationships and belongingness. However, possessing overly positive perceptions of one's status does lead to decreased social acceptance, and thus, the individual's need for self-esteem in this case is working against the need to socially belong. Consistent with prior theorizing, the need to belong outweighs the individual's need to inflate self-esteem.

\section{References}

Aiken, L. S., \& West, S. G. (1991). Multiple regression: Testing and interpreting interactions. Newbury Park, CA: Sage.

Allison, S. T., Messick, D. M., \& Goethals, G. R. (1989). On being better but not smarter than others: The Muhammad Ali effect. Social Cognition, 7, 275-295.

Anderson, C., \& Berdahl, J. L. (2002). The experience of power: Examining the effects of power on approach and inhibition tendencies. Journal of Personality and Social Psychology, 83, 1362-1377.

Anderson, C., John, O. P., Keltner, D., \& Kring, A. M. (2001). Who attains social status? Effects of personality traits and physical attractiveness in social groups. Journal of Personality and Social Psychology, 81, 116-132.

Aron, A., Melinat, E., Aron, E. N., Vallone, R. D., \& Bator, R. (1997). The experimental generation of interpersonal closeness: A procedure and some preliminary findings. Personality and Social Psychology Bulletin, 23, 363-377.

Bales, R. F. (1950). Interaction process analysis: A method for the study of small groups. Chicago: University of Chicago Press.

Barkow, J. H. (1975). Prestige and culture: A biosocial interpretation. Current Anthropology, 16, 553-562.

Baumeister, R. F. (1998). The self. In D. T. Gilbert, S. T. Fiske, \& G. Lindzey (Eds.), The handbook of social psychology (4th ed., Vol. 1, pp. 680-740). Boston: McGraw-Hill.

Baumeister, R. F., \& Leary, M. R. (1995). The need to belong: Desire for interpersonal attachments as a fundamental human motivation. Psychological Bulletin, 117, 497-529.

Berger, J., Cohen, B. P., \& Zelditch, M. (1972). Status characteristics and social interaction. American Sociological Review, 37, 241-255.

Berger, J., Rosenholtz, S. J., \& Zelditch, M. (1980). Status organizing processes. Annual Review of Sociology, 6, 479-508.

Blau, P. M. (1964). Exchange and power in social life. New York: Wiley. Bryk, A., \& Raudenbush, S. W. (1992). Hierarchical linear models for social and behavioral research: Applications and data analysis methods. Newbury Park, CA: Sage.
Bugental, D. B., \& Lewis, J. C. (1999). The paradoxical misuse of power by those who see themselves as powerless: How does it happen? Journal of Social Issues, 55, 51-64.

Buss, D. M. (1999). Human nature and individual differences: The evolution of human personality. In L. A. Pervin \& O. P. John (Eds.), Handbook of personality: Theory and research (2nd ed., pp. 31-56). New York: Guilford Press.

Buss, D. M., \& Kenrick, D. T. (1998). Evolutionary social psychology. In D. T. Gilbert, S. T. Fiske, \& G. Lindzey (Eds.), The handbook of social psychology (4th ed., Vol. 2, pp. 982-1026). Boston: McGraw-Hill.

Clark, C. (1990). Emotions and micropolitics in everyday life: Some patterns and paradoxes of "place." In T. D. Kemper (Ed.), Research agendas in the sociology of emotions (pp. 305-333). Albany: State University of New York Press.

Colvin, C. R., Block, J., \& Funder, D. C. (1995). Overly positive selfevaluations and personality: Negative implications for mental health. Journal of Personality and Social Psychology, 68, 1152-1162.

Cosmides, L., Tooby, J., \& Barkow, J. H. (1992). Introduction: Evolutionary psychology and conceptual integration. In J. H. Barkow, L. Cosmides, \& J. Tooby (Eds.), The adapted mind: Evolutionary psychology and the generation of culture (pp. 3-18). New York: Oxford University Press.

Cronbach, L. J. (1955). Processes affecting scores on "understanding others" and "assumed similarity." Psychological Bulletin, 52, 177-193.

Dunning, D., Leuenberger, A., \& Sherman, D. A. (1995). A new look at motivated inference: Are self-serving theories of success a product of motivational forces? Journal of Personality and Social Psychology, 69, $58-68$.

Dunning, D., Meyerowitz, J. A., \& Holzberg, A. D. (1989). Ambiguity and self-evaluation: The role of idiosyncratic trait definitions in self-serving assessments of ability. Journal of Personality and Social Psychology, 57, 1082-1090.

Flynn, F. J. (2003). How much should I give and how often? The effects of generosity and frequency or favor exchange on social status and productivity. Academy of Management Journal, 46, 539-553.

Flynn, F. J., \& Bohms, V. (2006). Just ask: How people underestimate the likelihood of compliance in favor exchange. Manuscript submitted for publication.

Frank, R. H. (1985). Choosing the right pond: Human behavior and the quest for status. New York: Oxford University Press.

Galinsky, A. D., Gruenfeld, D. H., \& Magee, J. C. (2003). From power to action. Journal of Personality and Social Psychology, 85, 453-466.

Gameworks Creations. (1995). Beyond Balderdash. Pawtucket, RI: Hasbro.

Gelb, L. H. (1981, May 31). How Haig is recasting his image. The New York Times, p. 23.

Gergen, K. J., \& Wishnov, B. (1965). Others' self-evaluations and interaction anticipation as determinants of self-presentation. Journal of Personality and Social Psychology, 2, 348-358.

Goffman, E. (1967). Interaction ritual. New York: Anchor Books.

Goldhamer, H., \& Shils, E. A. (1939). Types of power and status. American Journal of Sociology, 45, 171-182.

Gosling, S. D., John, O. P., Craik, K. H., \& Robins, R. W. (1998). Do people know how they behave? Self-reported act frequencies compared with on-line codings by observers. Journal of Personality and Social Psychology, 74, 1337-1349.

Greenwald, A. G. (1980). The totalitarian ego: Fabrication and revision of personal history. American Psychologist, 35, 603-618.

Heaven, P. C. (1986). Authoritarianism, directiveness, and self-esteem revisited: A cross-cultural analysis. Personality and Individual Differences, 7, 225-228.

Heine, S. J., \& Lehman, D. R. (1997). The cultural construction of self-enhancement: An examination of group-serving biases. Journal of Personality and Social Psychology, 72, 1268-1283.

Heine, S. J., Lehman, D. R., Markus, H., \& Kitayama, S. (1999). Is there 
a universal need for positive self-regard? Psychological Review, 106, 766-794

Hogan, R. (1983). A socioanalytic theory of personality. In M. Page (Ed.), Nebraska symposium on motivation: Vol. 30. Personality-Current theory and research (pp. 55-89). Lincoln: University of Nebraska Press.

Homans, G. C., (1951). The human group. London: Routledge \& Kegan Paul. John, O. P., \& Robins, R. W. (1994). Accuracy and bias in self-perception: Individual differences in self-enhancement and the role of narcissism. Journal of Personality and Social Psychology, 66, 206-219.

Jones, S. C., \& Shrauger, J. S. (1970). Reputation and self-evaluation as determinants of attractiveness, Sociometry, 33, 276-286.

Jussim, L. (1991). Social perception and social reality: A reflectionconstruction model. Psychological Review, 98, 54-73.

Keltner, D., \& Anderson, C. (2000). Saving face for Darwin: The functions and uses of embarrassment. Current Directions in Psychological Science, 9, 187-192.

Keltner, D., Gruenfeld, D. H., \& Anderson, C. (2003). Power, approach, and inhibition. Psychological Review, 110, 265-284.

Kenny, D. A. (1994). Interpersonal perception. New York: Guilford Press.

Kenny, D. A. (1995). SOREMO Version V.2: A FORTRAN program for the analysis of round-robin data structures. Unpublished manuscript, University of Connecticut.

Kenny, D. A. (1996). The design and analysis of social-interaction research. Annual Review of Psychology, 47, 59-86.

Kenny, D. A., \& Campbell, D. T. (1999). On the measurement of stability in over-time data. Journal of Personality, 57, 445-481.

Kenny, D. A., Kashy, D. A., \& Cook, W. L. (2006). Dyadic data analysis. New York: Guilford Press.

Kenny, D. A., \& La Voie, L. (1984). The social relations model. In L. Berkowitz (Ed.), Advances in experimental social psychology (Vol. 18, pp. 142-182). Orlando, FL: Academic Press.

Krebs, D. L., \& Denton, K. (1997). Social illusions and self-deception: The evolution of biases in person perception. In J. A. Simpson \& D. T. Kenrick (Eds.), Evolutionary social psychology (pp. 21-48). Mahwah, NJ: Erlbaum.

Kruger, J., \& Dunning, D. (1999). Unskilled and unaware of it: How difficulties in recognizing one's own incompetence lead to inflated selfassessments. Journal of Personality and Social Psychology, 77, 1121-1134.

Kwan, V. S., John, O. P., Kenny, D. A., Bond, M. H., \& Robins, R. W. (2004). Reconceptualizing individual differences in self-enhancement bias: An interpersonal approach. Psychological Review, 111, 94-110.

Leary, M. R., Cottrell, C. A., \& Phillips, M. (2001). Deconfounding the effects of dominance and social acceptance on self-esteem. Journal of Personality and Social Psychology, 81, 898-909.

Lee, M. T., \& Ofshe, R. (1981). The impact of behavioral style and status characteristics on social influence: A test of two competing theories. Social Psychology Quarterly, 44, 73-82.

Maslow, A. H. (1968). Toward a psychology of being. New York: Van Nostrand.

Mazur, A. (1973). A cross-species comparison of status in small established groups. American Sociological Review, 38, 513-530.

McClelland, G. H., \& Judd, C. M. (1993). Statistical difficulties of detecting interactions and moderator effects. Psychological Bulletin, 114, 376-390.

Messick, D. M., Bloom, S., Boldizar, J. P., \& Samuelson, C. D. (1985). Why we are fairer than others. Journal of Experimental Social Psychology, $21,480-500$.

Morf, C. C., \& Rhodewalt, F. (2001). Unraveling the paradoxes of narcissism: A dynamic self-regulatory processing model. Psychological Inquiry, 12, 177-196.

Paulhus, D. L. (1998). Interpersonal and intrapsychic adaptiveness of trait self-enhancement: A mixed blessing? Journal of Personality and Social Psychology, 74, 1197-1208.
Pfeffer, J., \& Cialdini, R. B. (1998). Illusions of influence. In R. M. Kramer $\&$ M. A. Neale (Eds.), Power and influence in organizations (pp. 1-20). Thousand Oaks, CA: Sage.

Powers, T. A., \& Zuroff, D. C. (1986). Interpersonal consequences of overt self-criticism: A comparison with neutral and self-enhancing presentations of self. Journal of Personality and Social Psychology, 54, 1054-1062.

Raghunathan, T. E., Rosenthal, R., \& Rubin, D. B. (1996). Comparing correlated but nonoverlapping correlations. Psychological Methods, 1, 178-183.

Raskin, R., Novacek, J., \& Hogan, R. (1991). Narcissistic self-esteem management. Journal of Personality and Social Psychology, 60, 911-918.

Ridgeway, C. L. (1982). Status in groups: The importance of motivation. American Sociological Review, 47, 76-88.

Ridgeway, C. L. (1987). Nonverbal behavior, dominance, and the basis of status in task groups. American Sociological Review, 52, 683-694.

Ridgeway, C. L., \& Berger, J. (1986). Expectations, legitimation, and dominance behavior in task groups. American Sociological Review, 51, 603-617.

Ridgeway, C. L., \& Diekema, D. (1989). Dominance and collective hierarchy formation in male and female task groups. American Sociological Review, 54, 79-93.

Robins, R. W., \& Beer, J. S. (2001). Positive illusions about the self: Short-term benefits and long-term costs. Journal of Personality and Social Psychology, 80, 340-352.

Robins, R. W., \& John, O. P. (1997). Effects of visual perspective and narcissism on self-perception: Is seeing believing? Psychological Science, 8, 37-42.

Roethlisberger, F. J., \& Dickson, W. J. (1938). Management and the worker: An account of a research program conducted by the Western Electric Company, Hawthorne Works, Chicago. Cambridge, MA: Harvard University Press.

Rogosa, D. (1980). A critique of cross-lagged correlation. Psychological Bulletin, 88, 245-258.

Srivastava, S., \& Beer, J. S. (2005). How self-evaluations relate to being liked by others: Integrating sociometer and attachment perspectives. Journal of Personality and Social Psychology, 89, 966-977.

Taylor, S. E., \& Brown, J. D. (1988). Illusion and well-being: A social psychological perspective on mental health. Psychological Bulletin, 103, 193-210.

Taylor, S. E., Lerner, J. S., Sherman, D. K., Sage, R. M., \& McDowell, N. K. (2003). Portrait of the self-enhancer: Well adjusted and well liked or maladjusted and friendless? Journal of Personality and Social Psychology, 84, 165-176.

Thibaut, J. W., \& Kelley, H. H. (1959). The social psychology of groups. New York: Wiley.

Weisman, S. R. (1982, June 26). Haig resigns over foreign policy course, but cites no issues; Reagan names Schultz. The New York Times, p. 1.

West, S. G., Biesanz, J. C., \& Pitts, S. C. (2000). Causal inference and generalization in field settings: Experimental and quasi-experimental designs. In H. T. Reis \& C. M. Judd (Eds.), Handbook of research methods in social and personality psychology (pp. 40-84). New York: Cambridge University Press.

Whyte, W. F. (1943). Street corner society: The social structure of an Italian slum. Chicago: Chicago University Press.

Wiggins, J. S. (1979). A psychological taxonomy of trait-descriptive terms: The interpersonal domain. Journal of Personality and Social Psychology, 37, 395-412.

Wright, R. (1994). The moral animal: The new science of evolutionary psychology. New York: Pantheon Books.

Received March 1, 2006

Revision received June 11, 2006

Accepted June 17, 2006 